Özgün araştırma makalesi

\title{
Gazi Üniversitesi Tıp Fakültesi Dudak Damak Yarıkları Konseyine başvuran bireyler ile ilgili deskriptif değerlendirme
}

\author{
Şadiye Bacık Tırank (iD, ${ }^{1}$ Ayşe Gülşen, ${ }^{2}$ \\ Belma Işık Aslan, ${ }^{3}$ Fatma Deniz Uzuner iD, ${ }^{3 *}$ \\ Neslihan Üçüncü, ${ }^{3}$ Kemal Fındıkçıoğlu, ${ }^{2}$ \\ Hakan Tutar, ${ }^{4}$ Bülent Gündüz ${ }^{5}$ \\ ${ }^{1}$ Dil ve Konuşma Terapisi Bölümü, Sağlık Bilimleri Fakültesi, \\ ${ }^{2}$ Plastik, Rekonstrüktif ve Estetik Cerrahi Anabilim Dalı, Tıp \\ Fakültesi, ${ }^{3}$ Ortodonti Anabilim Dalı, Diş Hekimliği Fakültesi, \\ ${ }^{4}$ Kulak Burun Boğaz Anabilim Dalı, Tıp Fakültesi, ${ }^{5}$ Odyoloji \\ Bölümü, Sağlık Bilimleri Fakültesi, Gazi Üniversitesi, Ankara, \\ Türkiye
}

\section{ÖZET}

AmAÇ: Gazi Üniversitesi Tıp Fakültesi Dudak Damak Yarıkları (DDY) Konseyine başvurmuş olan hastaların demografik özelliklerini incelemek, yarık tiplerini, sendrom/ek anomali varlığını ve tedavi ihtiyaçlarını belirlemektir.

GeReÇ Ve Yöntem: Bu retrospektif çalışmada 2014-2018 yılları arasında konseye ilk kez başvuran 155 bireye (97 erkek, 58 kadın) ait kayıtlar değerlendirildi. Anamnez, klinik formu, konsey değerlendirmesi sürecinde alınan konuşma kayıtları, kulak burun boğaz muayenesi sonuçları, plastik cerrahi ve ortodonti bölümlerinin uygulamalarına ait veriler dijital ortama aktarıldı. Elde edilen verilerin istatistiksel değerlendirilmesi; tanımlayıcı istatistiksel analiz ve verilerin frekanslarının belirlenmesi ile yapıldı.

BULGULAR: Konseye her coğrafi bölgeden ve farklı şehirlerden başvuru yapıldığı saptandı. Hastaların yaşı 9 gün ile 57 yıl aralığında olup ortalama yaşları 10.2 yıldı. Konseye en fazla 0-6 yaş arasındaki bireylerin (\%40.7) başvurduğu, bunu 11-18 yaş arasındaki bireylerin (\%31.6) izlediği saptandı. Ayrıca, 19 hastanın ailesinde son 3 kuşakta DDY öyküsü olduğu, 29 bireyde akraba evliliği olduğu gözlendi. Bireylerde en fazla yumuşak, sert damak ile alveol ve dudağın tek tarafı yarıklarına (Veau III) rastlandı ( $n=71$, \%45.8). DDY ile birlikte en sık görülen şikayetler ise işitme kaybı ( $n=87)$, dil ve konuşma bozukluğu $(n=61)$, kalp rahatsızlığı $(n=8)$ ve mental retardasyondu $(n=4)$. Eşlik eden sendrom olarak; 2 vakada Pierre Robin sekansı, 1'er vakada Van Der Woude sendromu, Goldenhar sendromu ve Cruzon sendromu bulundu.

Makale gönderiliş tarihi: 25 Temmuz 2020; Yayına kabul tarihi: 25 Mart 2021 * Iletișim: Dr. Fatma Deniz Uzuner, Gazi Üniversitesi Diş Hekimliği Fakültesi,

Ortodonti Anabilim Dalı, 06510, Emek, Ankara, Türkiye;

E-posta: fduzuner@yahoo.com.tr
Sonuç: Konseye en fazla 0-6 yaş aralığındaki DDY'li bireylerin başvurduğu saptandı. Bireylerin ailelerinin \%18.7'sinde akraba evliliği olduğu gözlendi. Tek taraflı DDY çift taraflı DDY'den fazla görüldü. DDY'li bireylere yüz anomalileri dışında çok farklı bölgelerde anomaliler eşlik edebilmekteydi. Ek problemlerden en sık görülen, işitme kaybıydı, ardından, dil ve konuşma bozukluğuydu, sendrom olarak ise Pierre Robin sekansı ve hemifasiyal mikrosomia idi.

ANAHTAR Kelimeler: Demografik analiz; demografik ve sağlık; disiplinlerarası iletişim; konuşma terapisi; odyoIoji; ortodonti

Kaynak Göstermek İçin: Bacık Tırank Ş, Gülşen A, Işık Aslan $B$, Uzuner FD, Üçüncü N, Fındıkçıoğlu K, Tutar H, Gündüz B. Gazi Üniversitesi Tıp Fakültesi Dudak Damak Yarıkları Konseyine başvuran bireyler ile ilgili deskriptif değerlendirme. Acta Odontol Turc 2022;39(1):10-5

Ерітӧв: Emine Kaygısız, Gazi Üniversitesi, Ankara, Türkiye

YAYIN HAKKI: @ 2022 Bacık Tırank ve ark. Bu eserin yayın hakkı Creative Commons Attribution License ile ruhsatlandırılmıştır. Sınırsız kullanım, dağıtım ve her türlü ortamda çoğaltım, yazarlar ve kaynağın belirtilmesi kaydıyla serbesttir.

Finansal Destek: Bulunmamaktadır.

ÇıKAR ÇATışmASı: Bulunmamaktadır.

[Abstract in English is at the end of the manuscript]

\section{GiRiş}

Dudak damak yarıkları (DDY) embriyolojik gelişimin 4 . ve 8. haftaları arasında bebeğin yüz bölgesindeki yapıların birleşme kusuru nedeniyle ortaya çıkan, multifaktöriyel etiyolojiye sahip baş-boyun bölgesinde sık görülen konjenital malformasyonlardır. ${ }^{1-4}$ Etiyolojisi tam olarak bilinmemekle beraber, genetik ve çevresel faktörlerin ortak etkileşiminin bu anomaliye sebep olduğu düşünülmektedir. ${ }^{1}$ Genetik kökenin etkisi bakımından DDY açısından pozitif bir aile öyküsü bulunan vakalarda, sonraki doğumlarda da DDY görülme riskinin arttığı bildirilmektedir. ${ }^{5,6}$ Dudak damak deformitelerinin dağılımı etnik köken, cinsiyet, coğrafya gibi çeşitli faktörlere göre değişim göstermektedir. ${ }^{7-9}$ Ülkemizde yapılan epidemiyolojik çalışmalarda da \%0.05 ile \%0.1 arasında görüldüğü bildirilmiştir. Cinsiyet açısından değerlendirildiğinde izole damak yarıkları kadınlarda daha fazla gö- 
rülmekte iken, dudak ve damak yarığının birlikte görülme sıklığı erkeklerde daha fazla olarak bulunmuştur.

Çoğunlukla non-sendromik olmakla birlikte DDY'ye \%3-22.4 oranında bir sendrom da eşlik edebilir. ${ }^{8,10} \mathrm{Bu}$ vakalarda sık görülen sendromlar Pierre Robin sekansı, Van der woude sendromu, Down sendromu, Di George sendromu, Goldenhar sendromu şeklinde ifade edilebilmektedir. ${ }^{10}$ Ayrıca bu vakalarda ek problemler de görülebilmektedir. DDY'ye sıklıkla iskelet sistemi, merkezi sinir sitemi, kardiyovasküler sistem anomalileri, göz ve kulak hastalıkları eşlik edebilmektedir. ${ }^{10-12}$ DDY ile doğan çocukların sahip olduğu çoklu problemler nedeniyle çeşitli alanlardaki intiyaçlarına cevap verebilmek ciddi bir multidisipliner ekip çalışmasını gerektirir. Bu ekip içinde Plastik ve Rekonstrüktif Cerrahi uzmanı, Kulak Burun Boğaz uzmanı, Dil ve konuşma terapisti, Ortodontist, Psikolog ve Odyolog yer almalıdır. Ülkemizde de bu disiplinlerin dahil olduğu DDY merkezlerine intiyaç artmaktadır. Bu merkezlere başvuran bireylerin/ ailelerinin özelliklerinin ve intiyaçlarının belirlenmesi ekiplere dahil olan disiplinlerin çeşitlendirilmesine rehber olacaktır.

Bu çalışmada Gazi Üniversitesi Dudak Damak Yarıkları Konseyine başvurmuş olan hastaların demografik özelliklerini incelemek, yarık tiplerinin dağılımını, sendrom ve ek anomali varlığını, tedavi ihtiyacına ait özelliklerini belirlemek amaçlandı.

\section{Gereç ve Yöntem}

Bu retrospektif çalışmanın etik onayı Gazi Üniversitesi Ölçme ve Değerlendirme Etik Alt Çalışma Grubundan alındı (No: 91610558-604-01.02). Çalışma için 20142018 yılları arasında Gazi Üniversitesi Tıp Fakültesi DDY konseyine ilk kez başvuran 155 bireye ait kayıtlar incelendi. Bu vakaların yaş, cinsiyet, yarık tipi, sendromik olma durumu, yaşadığı şehir, ek anomali bulunma durumu, fistül varlığı, alveolar yarık varlığı, ailede DDY öyküsü, akraba evliliği öyküsü, işitme durumu, yapılan ortodontik uygulamalar, operasyon türü ve zamanlaması değerlendirildi.

Hastalardaki yarık tipinin değerlendirilmesinde Veau sınıflaması dikkate alındı. Bu sınıflamaya göre: Veau I; yumuşak damak yarığını, Veau II; sert ve yumuşak damak yarı̆̆ını, Veau III; yumuşak,sert damak ile alveol ve dudağın tek taraflı yarıklarını ve Veau IV; yumuşak, sert damak ile alveol ve dudağın çift tarafIı yarıklarını tanımlamaktadır. Ayrıca submuköz yarığı olan bireyler de çalışmaya dahil edildi.

Elde edilen veriler SPSS 22.0 programı (SPSS Inc., Chicago, IL ABD) ile analiz edildi. Verilerin istatistiksel değerlendirilmesi tanımlayıcı istatistiksel analiz ve verilerin frekanslarının belirlenmesi ile yapıldı.

Tablo 1. Bireylerin yaş dönemlerine göre dağılımı

\begin{tabular}{lllllll}
\hline & $\mathbf{0 - 3 6}$ ay & $\mathbf{3 - 6}$ yaş & $\mathbf{7 - 1 0}$ yaş & $\mathbf{1 1 - 1 8}$ yaş & $\mathbf{1 8 +}$ yaş & Toplam \\
\hline Birey sayısı; $\mathbf{n}(\%)$ & $33(\% 21.3)$ & $30(\% 19.4)$ & $23(\% 14.8)$ & $49(\% 31.6)$ & $20(\% 12.9)$ & $155(\% 100)$ \\
Yaş (ortalama \pm standart sapma) & $1.3 \pm 1.0$ & $4.7 \pm 0.8$ & $8.2 \pm 0.8$ & $14.5 \pm 2.4$ & $24.5 \pm 9.3$ & $10.2 \pm 8.3$ \\
\hline
\end{tabular}

Tablo 2. Bireylerin yarık tiplerine göre dağılımları

\begin{tabular}{ll}
\hline Sınıflama & Birey sayısı; $\mathbf{n}(\%)$ \\
\hline Veau I & $5(\% 3.2)$ \\
Veau II & $35(\% 22.6)$ \\
Veau III & $71(\% 45.8)$ \\
Veau IV & $34(\% 21.9)$ \\
Submuköz yarık & $10(\% 6.5)$ \\
\hline Toplam & $155(\% 100)$ \\
\hline
\end{tabular}

\section{Bulgular}

\section{Cinsiyet dağılımı}

Çalışma kapsamında değerlendirilen 155 hastanın 97'si (\%62.6) erkek, 58'i (\%37.4) kadındı.

\section{Yaş dağılımı}

Yaş gruplarına göre bireylerin dağılımı Tablo 1'de gösterilmektedir. Konseye başvuran hastaların yaşları 9 gün ile 57 yıl arasında değişmekteydi (Ortalama 10.2 \pm 8.3). Konseye en fazla 0-6 yaş arasındaki bireylerin
(\%40.7) başvurduğu, bunu 11-18 yaş arasındaki bireylerin (\%31.6 ) izlediği saptandı (Tablo1).

\section{Yarık tipleri}

Hastaların yarık tiplerine göre dağılımları değerlendirildiğinde; 5 (\%3.2) birey Veau I, 35 (\%22.6) birey Veau II, 71 (\%45.8) birey Veau III, 34 (\%21.9) birey Veau IV, 10 (\%6.5) birey submuköz yarığa sahipti (Tablo 2).

\section{Cerrahi uygulamaların zamanı}

Dudak operasyonunun en erken 20. gün, en geç 12 . ay (ortalama 5.6 ayda); damak operasyonunun ise en erken 4. ay, en geç 9 yaşında (ortalama 28.8 aylıkken) yapıldığı saptandı. Hastaların 20'sinde fistül olduğu saptandı ve bu hastaların 6'sı merkezimizde fistül operasyonu geçirdi.

\section{Ağız içi muayene bulguları}

Yapılan ağız içi muayenede; 20 vakada uvulanın kısa olduğu, 13 vakada bifid uvula varlığı ve 1 vakada uvulanın sağa deviye olduğu gözlendi. Velofarengeal değerlendirmelerinde; DDY bulunan 42 vakada disfonksiyon gözlendi. 


\section{Aile öyküsü}

Aile öyküsüne bakıldığında; 19 (\%12.2) vakanın ailesinde son 3 kuşakta DDY öyküsü olduğu, 136 vakada aile öyküsü bulunmadığı belirlendi. Akraba evliliği açısından bakıldığında 29 vakada (\%18.7) 2. ve 3. dereceden akrabalık olduğu, 126 vakada akrabalık olmadığı saptandı.

\section{Coğrafi dağılım}

Hastaların yaşadıkları şehir Tablo 3'te özetlenmiştir. Her coğrafi bölgeden ve farklı şehirlerden başvuru yapıldığı gözlendi. En sık başvuru 90 (\%58) kişi ile Ankara'dan oldu. Bir hasta yabancı uyruklu olup, ailesi Suriye'den göç eden bir ailenin çocuğuydu.

\section{Eşlik eden sendrom/anomaliler}

DDY'li bireylere eşlik eden sendrom ya da anomaliler Tablo 4'te gösterilmektedir. Bireylerde en sık rastlanan problemler işitme kaybı (\%56.1) ile dil ve konuşma bozukluğuydu (\%39.4). Daha düşük oranda gözlenen problemler görünme sıklığına göre sıralandığında parmak anomalileri, hidrosefali, göz problemi, öğrenme güçlüğü, gelişim geriliği, skolyoz, tiroid problemi, atrezik kulak ve kromozom (46. kromozom) anomalisiydi. Sendrom olarak ise; Pierre Robin sekansı, hemifasiyal mikrosomia, Van Der Woude sendromu, Goldenhar sendromu ve Cruzon sendromu gözlendi. Bu anomaliler bazı vakalarda birlikte görülmekteydi.

\section{Konsültasyon istenen branşlar}

Konseye başvuran bireylerden 47'sinin (\%30.3) değerlendirilmek üzere konseydeki branşlar haricinde; genetik $(n=4)$, pediatri $(n=25)$, psikiyatri $(n=5)$, endokrin $(n=2)$, beyin cerrahisi $(n=3)$, nöroloji $(n=3)$, ortopedi $(n=1)$ ve diş-çene protezi $(n=4)$ bölümlerine yönlendirildiği saptandı.

Tablo 3. Konseyde değerlendirilen kişilerin yaşadıkları yerler ve sayıları $(N=155, \% 100)$

\begin{tabular}{llll}
\hline Şehir & Birey sayısı (\%) & Şehir & Birey sayısı (\%) \\
\hline Adıyaman & $1(0.6)$ & Isparta & $1(0.6)$ \\
Afyon & $3(1.9)$ & Kahramanmaraş & $1(0.6)$ \\
\hline Ağrı & $1(0.6)$ & Kastamonu & $3(1.9)$ \\
Aksaray & $1(0.6)$ & Kayseri & $3(1.9)$ \\
Amasya & $1(0.6)$ & Kırıkkale & $2(1.3)$ \\
Ankara & $90(58)$ & Kırşehir & $2(1.3)$ \\
Antalya & $2(1.3)$ & Konya & $1(0.6)$ \\
Bartın & $1(0.6)$ & Kütahya & $1(0.6)$ \\
Batman & $1(0.6)$ & Manisa & $1(0.6)$ \\
Bilecik & $1(0.6)$ & Mardin & $1(0.6)$ \\
Bolu & $1(0.6)$ & Muğla & $1(0.6)$ \\
Çankırı & $4(2.6)$ & Niğde & $3(1.9)$ \\
Çorum & $6(3.9)$ & Suriye & $1(0.6)$ \\
Düzce & $2(1.3)$ & Şanlıurfa & $1(0.6)$ \\
Erzincan & $1(0.6)$ & Van & $1(0.6)$ \\
Eskişehir & $6(3.9)$ & Yozgat & $3(1.9)$ \\
Hatay & $1(0.6)$ & Zonguldak & $6(3.9)$ \\
\hline & & &
\end{tabular}

Tablo 4. Bireylerde gözlenen ek anomali ve sendromlar

\begin{tabular}{ll}
\hline Ek problem & Görülme sıklığı; n (\%) \\
\hline İşitme kaybı & $87(\% 56.1)$ \\
\hline Dil ve konuşma bozukluğu & $61(\% 39.4)$ \\
\hline Kalp problemleri & $8(\% 5.2)$ \\
\hline Mental retardasyon & $4(\% 2.6)$ \\
\hline Parmak anomalisi & $3(\% 1.9)$ \\
\hline Hidrosefali & $2(\% 1.3)$ \\
\hline Göz problemi & $2(\% 1.3)$ \\
\hline Öğrenme güçlüğü & $2(\% 1.3)$ \\
\hline Hemifasiyal mikrosomia & $2(\% 1.3)$ \\
\hline Pierre Robin sekansı & $2(\% 1.3)$ \\
\hline Gelişim geriliği & $1(\% 0.6)$ \\
\hline Skolyoz & $1(\% 0.6)$ \\
\hline Tiroid problemi & $1(\% 0.6)$ \\
\hline Kromozom anomalisi & $1(\% 0.6)$ \\
\hline Atrezik kulak & $1(\% 0.6)$ \\
Van der Woude sendromu & $1(\% 0.6)$ \\
\hline Goldenhar sendromu & $1(\% 0.6)$ \\
\hline Cruzon sendromu & $1(\% 0.6)$ \\
\hline
\end{tabular}

\section{TARTIŞMA}

Hem aileler hem de çocuklar için önemli tıbbi ve psikolojik problemlere yol açabilen DDY anomalilerinin zamanında, uygun tedavisinin yapılması ve normal büyümenin sağlanması için farklı disiplinlerin bir arada olduğu DDY merkezlerine intiyaç olduğu görülmektedir. Bu amaçla Üniversitemiz bünyesinde oluşturulan DDY Konseyi, Plastik ve Rekonstrüktif Cerrahi, Kulak Burun Boğaz, Dil ve Konuşma Terapisi, Ortodonti ve Odyoloji disiplinlerini içermektedir. Konseye başvuran bireylerin/ ailelerinin özelliklerinin ve ihtiyaçlarının belirlenmesi ekiplere dahil olan disiplinlerin çeşitlendirilmesine rehber olacaktır. Ayrıca, bu vakalara uygulanan tedavi seçeneklerinin belirlenmesi bu vakalar için uygulanması gereken eğitsel ve rehabilitatif süreçlerin saptanmasına katkı sağlayacaktır. Bu amaçla konseyimize başvuran hastalara ait kayıtlar retrospektif olarak değerlendirildi.

DDY ile ilgili tüm dünyada kabul görmüş ortak bir terminoloji ve sınıflandırma sistemi henüz olmadığından pek çok araştırmacı kendi sınıflama yöntemini geliştirmiştir. Çalışmalarda sıklıkla kullanılan sınıflandırmalar; Davies ve Ritchie'nin, Sadler'in, Veau'nun, Kernahan ve Stark'ın sınıflandırmaları şeklinde özetlenebilir. ${ }^{13,14}$ Bu çalışmada Veau sınıflaması kullanıldı. Çalışmamızda en fazla yumuşak ve sert damak ile alveol ve dudağın tek taraflı yarıkları'na (Veau III) rastlandı. Tek taraflı DDY, çift taraflı DDY'den daha fazla görüldü. Bu durum Sekhon ve arkadaşlarının ${ }^{15}$ çalışmasıyla uyumludur. En az ise, yumuşak damak yarığı (Veau I) gözlendi.

DDY'li bireylerde problemlerin erken tespiti ve zamanında müdahalesi oldukça önemlidir. ${ }^{16-18}$ Konseyimize de erken yaş döneminde başvuru yapanların oranlarının daha yüksek olduğu; en fazla 0-6 yaş aralığındaki (\%40.7) bireylerin başvurduğu saptandı. Toplamda 
değerlendirilen 155 bireyin 33'ü (\%21.3) 0-36 ay aralığındadır. Bu dönemde yapılan müdahaleler; beslenme plakları ve preoperatif nazoalveolar molding (PNAM) uygulaması, ${ }^{16}$ dudak/damak onarımları, beslenme önerileri, işitme değerlendirmeleri, dil değerlendirmeleri, genel gelişim değerlendirmesi ve ağız hijyeni eğitimi şeklindedir. Bireylerin \%19.4'ünün ise 3-6 yaş aralığında olduğu görüldü. Bu dönemde yapılan müdahaleler; dil-konuşma değerlendirmeleri, işitme takibi, ortodontik ve pedodontik kontrol, plastik cerrahi kontrolü, velofarengeal disfonksiyon (VFD) açısından değerlendirme ve gerekiyorsa tedavilerinin yapılması şeklindedir. Bireylerin 23'ü (\%14.8) ise 7-10 yaş aralığında bulundu. Bu dönemde; cerrahi, ortodontik ve dil konuşma takibini ilgilendiren uygulamaların yapıldığı saptandı. Bu uygulamalar; diş-çene ve yüz gelişiminin takibi, gerekliyse ortodontik tedavinin planlanması, alveolar greftleme, konuşma bozukluklarına yönelik cerrahi müdahaleleri içermektedir. 0-6 yaş aralığından sonra en fazla başvuru 11-18 yaş (\%31.6) aralığında bulundu. Bu dönemde; diş-çene ve yüz anomalilerine gerekli müdahalelerin planlanması, distraksiyon osteogenezis uygulaması, dudak ve burun bozukluklarının değerlendirilmesi şeklinde müdahaleler yapılmaktadır. Konseye başvuru yapan bireyler içinde 18 ve üzeri yaşa sahip birey sayısının (\%12.9) daha az olduğu saptandı. Büyüme ve gelişimi bitmiş olan bu bireylere bu dönemde; ortognatik cerrahi, son estetik işlemlerin tamamlanması, rutin ağız hijyeni, dil-konuşma değerlendirmeleri, cerrahi ve ortodontik kontroller ve gerekli görülen tedavilerin yapılması şeklinde müdahale edilmektedir.

Konseye en fazla 0-6 yaş ve ardından 11-18 yaş aralığındaki bireylerin başvurduğu göz önünde bulundurulursa ve bu yaşlarda yapılan tedavi uygulamaları dikkate alınırsa; bu merkezler içinde özellikle çocukluk dönemiyle ilgilenen pediatri, pedodonti, ortodonti, çocuk psikoloğu, pedagog gibi disiplinlerin bulunması ideal tedavilerin elde edilmesine önemli katkı sağlayacaktır.

Çalışmamızda DDY'lerdeki cinsiyet farklılığı incelendiğinde erkek vakaların sayısının fazla olduğu görülmektedir. Bu sonuç, cinsiyet açısından dudak damak yarıklarının erkeklerde daha sık olduğunu vurgulayan literatür bulgularıyla uyumludur. ${ }^{6,19}$

$\mathrm{Bu}$ çalışmanın amaçlarından biri de, dudak-damak yarığı mevcut olan hastalarda ailede DDY öyküsü olmasının etkisini değerlendirmektir. DDY açısından pozitif bir aile öyküsü bulunan vakalarda, sonraki doğumlarda da DDY görülme riskinin arttığı bildirilmektedir. ${ }^{5}$ Aile çalışmalarına bakıldığında tekrarlama riskinin tek taraflıdan çift taraflıya ve sadece dudak yarığından, dudak damak yarığına doğru şiddetlenen bir artış gösterdiği belirtilmektedir. ${ }^{7}$ Literatürde bir çocukta damak yarığı varsa diğer çocukta oluşma sıklığı \%2, ebeveynlerden birinde varsa \%6, hem ebeveynlerden biri hem de bir çocukta varsa oran \%15 olarak bildirilmiştir. ${ }^{5,6}$ Daha önce farklı ülkelerde aile öyküsü üzerine yapılan çalışmalara bakıldığında, Çekoslovakya'da \%18, Polonya'da \%19 ve Brezilya'da \%35 olarak farklı oranlarda pozitif aile öyküsü rapor edilmiştir. ${ }^{6,20,21}$ Bizim çalışmamızda ise \%12.2 oranında ailede DDY öyküsü gözlendi. Çalışmamız ile diğer çalışma bulguları arasındaki farklııı ırksal kültürel farklılıklara bağlı olabilir.

DDY bir sendromla ilişkili veya non-sendromik olabilir. Anomalilerin ve sendromların DDY'ye eşlik etme oranlarını incelediğimizde, farklı ırklar arasında eşlik eden ek anomalilerin çeşidi ve oranı farklılıklar göstermektedir. Bu vakalarda sıklıkla ek bir anomali saptanmazken, bazı olgularda doğumsal malformasyonlar görülebilmektedir. ${ }^{10,22} \mathrm{Bu}$ yüzden yarık dudak ve damaklı olgular ayrıntılı olarak incelenmelidir. DDY'nin sendromlarla birliktelik insidansı \%3 ile \%22.4 arasında bildirilirken; ülkemizde yürütülmüş bir çalışmada vakaların \%4.4'ünün sendromik olduğu saptanmıştır ve en sık Pierre Robin sekansı görüldüğü bildirilmiştir. ${ }^{10} \mathrm{Bu}$ çalışmada ise; 2 vakada Pierre Robin sekansı, 1 vakada Van Der Woude sendromu, 1 vakada Goldenhar sendromu, 1 vakada Cruzon sendromu gözlendi. Bu çalışmanın bulgusu sendromlar içinde en sık Pierre Robin sekansının görüldüğünü bildiren çalışmalarla benzer şekildedir. ${ }^{10,23}$

Ayrıca, literatürde izole damak yarığı vakalarında \%13.7, DDY vakalarında ise \%11.4 ek malformasyonlar bildirilmiştir. ${ }^{10,23,24}$ Eşlik eden malformasyonlar ekstrakranial iskelet sistemi, kraniofasial yapılar, kardiyovasküler sistem, merkezi sinir sistemi, ürogenital sistem, göz ve kulak hastalıkları ile ilgili bulunmuştur. ${ }^{10,11}$ DDY ile birlikte en fazla işitme problemlerinin saptandığı bildirilmektedir. ${ }^{23,24}$ Damak yarığı popülasyonunda işitme kaybı insidansına ilişkin \%3 ile \%90 arasında değişen çeşitli raporlar mevcuttur. ${ }^{15,19,23-25} \mathrm{Bu}$ çalışmada da en sık görülen ek anomali \%56.1 oranı ile işitme kaybı olmuştur. Bu bakımdan literatürde de vurgulandığı üzere DDY'li çocuklarda düzenli otolojik ve odyolojik takibin yapılması önemlidir. ${ }^{23}$ İşitme kaybından sonra diğer sık görülen ek anomali \%39.4 oranılla dil ve konuşma bozukluğu olarak izlendi. Ayrıca, \%5.2 vakada kalp problemi, \%2.6 vakada da mental retardasyon saptandı.

Yapılan değerlendirmenin sonunda çalışmamıza katılan bireylerin yaklaşık 1/3'ünün ( $n=47, \% 30)$ çeşitli bölümlere konsültasyona gönderildiği tespit edildi. Bu durum DDY'li bireylerde multi/interdisipliner çalışmanın önemini ortaya koymaktadır. DDY'li bireylerin sahip oldukları problemler ve intiyaçları dikkate alındığında multidisipliner ekip içinde; Plastik ve Rekonstrüktif Cerrahi, Ortodonti, Oral Maksillofasiyal Cerrahi, Kulak Burun Boğaz, Dil ve Konuşma Terapisi, Odyoloji disiplinlerinin yanı sıra Genetik, Endokrin, Kardiyoloji, Kalp Damar Cerrahisi, Psikoloji, Pediatri, ve diş problemlerine yönelik olarak Pedodonti ve Protez bölümlerinin de yer alması faydalı olacaktır.

Gazi Üniversitesi Tıp Fakültesi DDY Konseyine başvuran bireylerin farklı şehir, coğrafya ve sosyo-kültürel bölgeden geldiği göz önüne alındığında; çalışma örnekleminin ülkemizin genelini temsil ettiği düşünülebilir. Dış merkezde opere olan vakaların içinde dudak/ damak operasyonlarının geç dönemde olduğu bireyler 
saptandı. Bu durum ülkemizde bu vakaların DDY ile çaIışan tecrübeli bir ekibe ulaşmakta güçlük yaşamaları ve gerekli tedavileri almakta gecikmeleri ile açıklanabilmektedir. Ailelerin başvuracakları merkezleri bilmesi ve kolayca ulaşabilmeleri erken müdahalelerin sayısını arttıracaktır. Bu nedenle DDY tedavi merkezlerinin arttırılması, var olan merkezlerin de daha etkili bir şekilde duyurulması gerekmektedir.

\section{Sonuç}

DDY'li bireylere zamanında, uygun tedavisinin yapılması ve normal büyümenin sağlanması için farklı disiplinlerin bir arada olduğu DDY merkezlerine intiyaç bulunmaktadır. DDY oluşumunda aile öyküsü ve akraba evliliğinin önemli etiyolojik nedenler olduğu göz önünde tutulduğunda; hastaların tedavileri kadar toplumun da bu anomalinin oluşma nedenleri konusunda bilinçlendirilmesine yönelik uygulamaların yapılması faydalı olacaktır.

\section{KAYNAKLAR}

1. Dixon MJ, Marazita ML, Beaty TH, Murray JC. Cleft lip and palate: understanding genetic and environmental influences. Nat Rev Genet 2011;12:167-78.

2. Grosen D, Chevrier C, Skytthe A, Bille C, Mølsted K, Sivertsen A, et al. A cohort study of recurrence patterns among more than 54,000 relatives of oral cleft cases in Denmark: support for the multifactorial threshold model of inheritance. J Med Genet 2010;47:162-8.

3. Stainer P, Moore GE. Genetics of cleft lip and palate: syndromic genes contribute to the incidance of non- syndromic clefts. Hum Mol Genet 2004;13 Spec No 1:R73-81

4. Moore KL, Persaut TVN, Torchia MG. İnsan Embriyolojisi, Klinik yönleri ile. 6th ed. İstanbul: Nobel Tıp Kitap Evleri; 2002

5. Curtis EJ, Fraser F, Warburton D. Congenital cleft lip and palate. Am $\mathrm{J}$ Dis Child 1961;102:853-7.

6. Peterka M, Peterková R, Halasková M, Tvrdek M, Fára M, Likovský Z. Sex differences in the incidence of clefts and the question of primary prevention in families with genetic risk. Acta Chir Plast 1996;38:57-60.

7. Nussbaum RL, Mclnnes RR, Willard HF. Thompson \& Thompson Genetics in Medicine. 7th ed. Philadelphia: W.B. Saunders Company; 2001.

8. Tunçbilek G. Dudak-damak yarıklarında kalıtım ve epidemiyoloji. In: Erk Y, Özgür F, editors. Dudak ve Damak Yarıkları. Ankara: İşkur Matbaacılık; 1999. p.7-16.

9. Yiğit AK, Oğuz ŞS, Dilmen U. Dudak ve damak yarıkları olan vakaların derlenmesi ve büyümelerinin izlemi. Jinekoloji-Obstetrik ve Neonatoloji Tıp Dergisi 2015;12:80-2.

10. Tunçbilek G, Özgür F, Balcı S. 1229 yarık dudak ve damak hastasında görülen ek malformasyon ve sendromlar. Çocuk Sağlığı ve Hastalıkları Dergisi 2004;47:172-6.

11. Goudy S, Lott D, Canady J, Smith RJ. Conductive hearing loss and otopathology in cleft palate patients. Otolaryngol Head Neck Surg 2006;134:946-8.

12. Flynn $T$, Möller $C$, Jönsson $R$, Lohmander $A$. The high prevalence of otitis media with effusion in children with cleft lip and palate as compared to children without clefts. Int J Pediatr Otorhinolaryngol 2009;73:1441-6.

13. Millard DR. Cleft Craft. The evolution of Its surgery. Vol I: The unilateral deformity. Boston: Little, Brown; 1976.

14. Sadler TW. Langman's Medical Embryology. 12th ed. Philadelphia: Wolters Kluwer Health/Lippincott Williams \& Wilkins; 2012.
15. Sekhon $P$, Ethunandan M, Markus A, Krishnan G, Rao CB. Congenital anomalies associated with cleft lip and palate- an analysis of 1623 consecutive patients. Cleft Palate-Cran J 2011;48:371-8.

16. Keçik D, Enacar A. Effects of nasoalveolar molding therapy on nasal and alveolar morphology in unilateral cleft lip and palate. $\mathrm{J}$ Craniofac Surg 2009;20:2075-80.

17. Pearson GD, Kirschner RE. Surgery for cleft palate and velopharyngeal dysfunction. Semin Speech Lang 2011;32:179-90.

18. Bicknell S, McFadden LR, Curran JB. Frequency of pharyngoplasty after primary repair of cleft palate. J Can Dent Assoc 2002;68:688-92.

19. Gorlin RJ, Cohen MM, Hennekam RCM. Syndromes of the Head and Neck. 4th ed. New York: Oxford University Press Inc; 2001.

20. Kot M, Kruk-Jeromini J. Analysis of family incidence of cleft lip and/ or palate. Med Sci Monit 2007;13:CR231-4.

21. Martelli DR, Bonan PR, Soares MC, Paranaiba LR, Martelli-Junior $\mathrm{H}$. Analysis of familial incidence of non-syndromic cleft lip and palate in a Brazilian population. Med Oral Patol Oral Cir Bucal 2010;15:898-901.

22. Yıldız M, Yalçın Ş. Yarık dudak ve damak. In Koç $C$, editor. Otolaringoloji baş ve boyun cerrahisi. Ankara: Güneş Tıp Kitabevleri; 2007. p.4052-85.

23. Gani B, Kinshuck A, Sharma R. A review of hearing loss in cleft palate patients. Int J Otolaryngol 2012;2012:548698.

24. Sheahan P, Miller I, Sheahan NJ, Earley MJ, Blayney AW. Incidence and outcome of middle ear disease in cleft lip and/or cleft palate. Int $\mathrm{J}$ Pediatr Otorhinolaryngol 2003;67:785-93.

25. Tırank ŞB, Keskin AGM, Atalık G, Kamışlı AGGŞ, Tutar H, Gündüz B. DamakıDudak Yarıklı Bireylerde Isşitme ve Dil Gelişiminin Değerlendirilmesi. H.Ü. Sağlık Bilimleri Fakültesi Dergisi 2017;4:72-85.

\section{A descriptive study on individuals referred to the Council of Cleft Lip and Palate of Gazi University}

\section{Abstract}

OвJестіVE: To assess the demographic characteristics and to determine the cleft types, the characteristics of the syndrome and additional anomalies, and treatment needs of patients referred to Gazi University Faculty of Medicine Cleft Lip and Palate (CLP) Council.

Materials AND Method: In this retrospective study, the records of 155 individuals (97 male, 58 female) referred to the council between 2014-2018 years were evaluated. Data obtained from anamnesis, clinical forms, speech records, ear-nose-throat examination results, records of plastic surgery, and orthodontic departments were transferred into digital media. The statistical evaluation of the obtained data was done by descriptive statistical analysis and determination of the frequencies of the data.

Results: It was determined that patients referred to the council were from all geographical regions and different cities of the country. The ages of the patients were between 9 days and 57 years and the mean age was 10.2 years. The individuals were mostly between 0-6 years old (40.7\%) followed by the patients between 11-18 years of age (31.6\%). Families of 19 cases had a history of CLP in the last 3 generations, and there were consanguineous marriages in 29 individuals. Unilateral cleft of the soft and hard palate and lip (Veau III) was the most common cleft type seen in the individuals $(n=71,45.8 \%)$. The most com- 
mon problems were hearing loss $(n=87)$, language and speech disorders $(n=61)$ heart problems $(n=8)$ and mental retardation $(n=4)$. The accompanying syndromes were found to be Pierre Robin sequence in 2 cases, and Van Der Woude syndrome, Goldenhar syndrome and Cruzon syndrome, each in 1 case.

CONCLUSION: The largest number of patients referred to the council were between 0-6 years of age. It was observed that $18.7 \%$ families of the individuals had consanguineous marriage. Unilateral CLP was seen more than bilateral
CLP. Individuals with CLP were found to have additional anomalies in many different regions other than the facial anomalies. The most common additional problems were hearing loss followed by language and speech disorders, and as a syndrome; Pierre Robin sequence and hemifacial microsomia.

KEYWORDS: Audiology; demographic analysis; demographic and health survey; interdisciplinary communication; orthodontics; speech therapy 